\title{
Mobile Augmented Reality for Cultural Heritage: Following the Footsteps of Ovid among Different Locations in Europe
}

\author{
Răzvan Gabriel Boboc ${ }^{1, *}$, Mihai Duguleană ${ }^{1} \mathbb{0}$, Gheorghe-Daniel Voinea ${ }^{1}$, \\ Cristian-Cezar Postelnicu ${ }^{1}$, Dorin-Mircea Popovici ${ }^{2}$ and Marcello Carrozzino ${ }^{3}$ \\ 1 Department of Automotive and Transport Engineering, Transilvania University of Brasov, \\ RO-500036 Brasov, Romania; mihai.duguleana@unitbv.ro (M.D.); daniel.voinea@unitbv.ro (G.D.V.); \\ cristian-cezar.postelnicu@unitbv.ro (C.-C.P.) \\ 2 Department of Mathematics and Computer Science, Ovidius University of Constanta, \\ 8700 Constanta, Romania; dmpopovici@univ-ovidius.ro \\ 3 Scuola Superiore Sant'Anna, 56127 Pisa, Italy; carrozzino@sssup.it \\ * Correspondence: razvan.boboc@unitbv.ro; Tel.: +40-745-987-710
}

Received: 31 January 2019; Accepted: 18 February 2019; Published: 22 February 2019

check for updates

\begin{abstract}
There are many examples of cultural events that distinguish people nationally. Celebrating this can bring people closer, as inhabitants of different countries share similar cultural values. This study investigates a sustainable way to enhance these types of events. On the occasion of the 2000-year anniversary of the death of the Roman poet Ovid, we propose a mobile augmented reality (MAR) application that contains historical information related to his life. As Ovid often stated in his last poems, he feared his work would be forgotten after his exile from Rome. This paper focuses on assessing whether this is the case, while also disseminating factual, historic data to people who tested the application. Experiments were conducted in Italy and Romania, in three different cities: Sulmona, Rome, and Constanta. Based on the results collected, four constructs were investigated: comprehensibility, manipulability, enjoyment, and usefulness. The results revealed that the usability of the MAR application, and the interaction metaphor, are appropriate for the general public. The MAR application provided a positive experience, and thus, increased the extent of the occasion.
\end{abstract}

Keywords: augmented reality; mobile phones; cultural heritage; evaluation

\section{Introduction}

The development of technology during the last decades has allowed the implementation of new ways of interacting between people and computers. The progress of digital information has also significantly affected the evolution of cultural heritage $(\mathrm{CH})$ dissemination [1], offering new possibilities for developing, e.g., the market of tourist services [2]. Whether it is a mobile application, an online catalog, or a social media exchange, these new paradigms are affecting all aspects of our lives, reshaping the way we communicate, learn, and approach the world around us [3]. One of these technologies that offers new ways of interacting is augmented reality (AR). This technology has a tremendous potential for the promotion and preservation of $\mathrm{CH}$. People are starting to be receptive-they want social and collaborative experiences that combine learning with having fun. $\mathrm{CH}$ organizations have to address their needs by creating innovative applications [4], and AR and mixed reality can make this happen. Computers have become more accessible and cheap enough for widespread applications in various fields [5]. CH can take advantage of this development by 
bringing cultural vestiges to light with the help of systems that can integrate computer-generated digital information with the physical world.

AR technology gives a different perception of reality, as it enriches reality with a computer-generated layer containing visual, audio, and tactile information. In this way, any object can be recreated and used as content for AR applications. Using a 'virtual' representation of a classic museum item has several advantages: it may incorporate dynamic elements, and it allows access to aspects of the artifact that may otherwise be hidden [6]. However, in order to build a complete and complex cultural representation via digital heritage technologies, developers must also understand how users interact with the system or interface [5]. When designing AR applications, it is important to choose the best combination of techniques for presenting the appropriate electronic information to the users. The content must meet their interests and needs in order to be accepted [7]. Thus, the usability evaluation of AR applications is of prime concern. Since AR is a relatively new technology, there are few papers that address the evaluation of AR interfaces, and furthermore, their sustainability in cases such as the one presented in this paper. For this reason, we have developed an AR application with the aim of investigating its usability, taking into account perceptual and ergonomic aspects.

The 2000th anniversary of the death of the Roman poet Publius Ovidius Naso, known as Ovid, was in 2017. This poet was "one of the most brilliant personalities of the Augustan Age", as described in [8]. Ovid was born in 43 BC, in the town of Sulmo (today: Sulmona), located in the middle of Italy, approximately $140 \mathrm{~km}$ from Rome. He lived in Rome after his studies, becoming famous and appreciated for his work. After his masterpiece, the "Metamorphoses", he was exiled in 8 AD to the isolated town of Tomis (today: Constanta, Romania), on the shore of the Black Sea at the outer edge of the Roman Empire. He was abruptly removed from the stimulating artistic and social community, which had nourished his extraordinarily successful poetic career, for reasons which were lost in the millennia. He died in Tomis 9 years later, still hoping for a pardon, which never came [9].

In line with the linguistic community, this anniversary highlights a good opportunity to give people a variety of ways to remember this great personality, whose vast influence and popularity continues to this day [10]. This heritage should not be lost, yet keeping it is not an easy task. The methodology of this study is based on bringing to life some creative moments from Ovid's existence. We have chosen three significant cities for the poet: Sulmona, Rome, and Constanta. By means of AR technologies and using mobile devices, we've created an application that was presented to the general public.

In this regard, the application tested had appropriate content for each location: Sulmona, where Ovid was born; Rome, where he has lived most of his life; and Tomis, where he died (Figure 1). Each version of the application recreates some aspects of his life, presenting his 3D animated model in the three stages of his life: as a child, as a famous public person, and as an exiled person in decline, but still artistically creative.

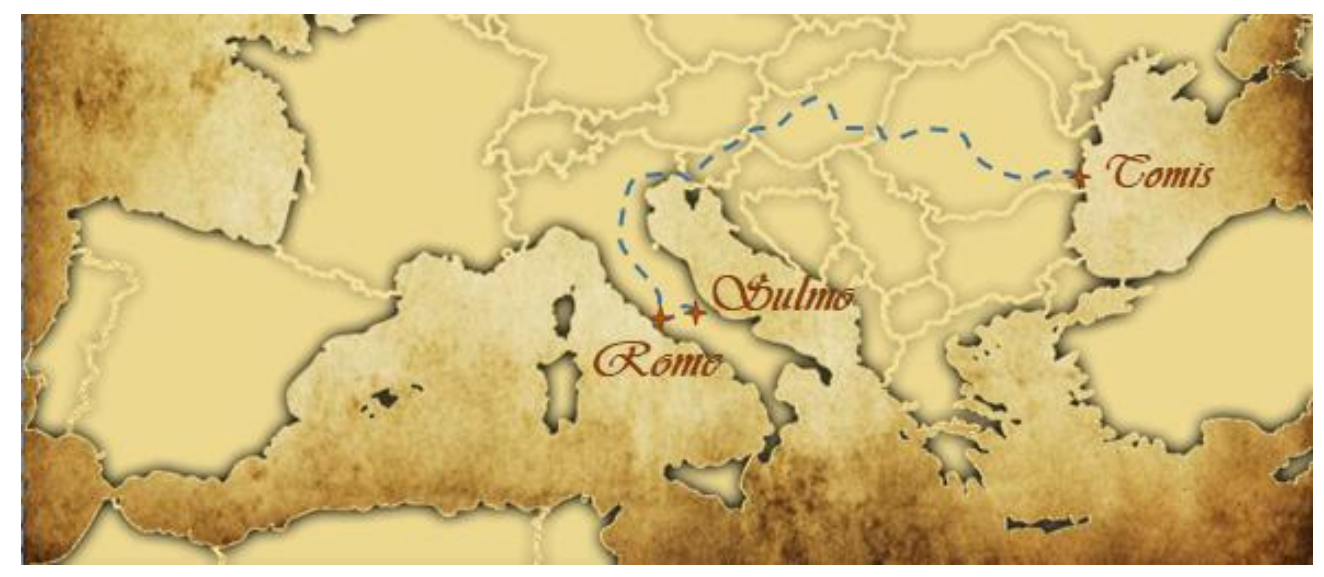

Figure 1. Three cities significant in Ovid's life, where the application was tested by the general public. 
$\mathrm{AR}$ and virtual reality (VR) are technologies that allow us to bring to life lost historical periods of time, while protecting the real artifacts for generations to come. From this point of view, the main objective of this research was to introduce mobile augmented reality (MAR) as a means to present $\mathrm{CH}$, and to sustainably reuse digital content for general public dissemination.

We proposed the corresponding research objectives: to model and design an attractive application that could be used by tourists and local citizens to learn more about the life of Ovid. To recreate the historical context of that time by using graphical representations enhanced with audio content. Finally, to evaluate the effectiveness of that application.

This article is structured as follows: Section 2 describes related work and sets the context of this paper. Section 3 describes the application and the experiment setup. Section 4 presents the evaluation results. In Section 5, the findings are summarized and, finally, Section 6 reports conclusions and future work.

\section{Related Work}

Preserving cultural heritage provides the reasoning to investigate the opportunities offered by digital technology. There is a vast body of work within the field of AR in $\mathrm{CH}$ contexts, especially for education, learning, and improving tourist experience [11-17].

From a historical perspective, AR was developed from VR, with the specificity that allows the visualization of both real and virtual objects at the same time. The first VR system is considered to be Sensorama machine, developed in the late 1950s [18], while the history of AR started in 1968 with the head-mounted display system developed by Ivan Sutherland. The term "augmented reality" was coined only in 1990 by Tom Caudell and David Mizell [19]. With the development of technology over time, the concept has evolved and the advancements in handheld computers have opened new opportunities for AR [1]. The first handheld mobile phone was presented by Motorola in 1973, and the first personal digital assistant (PDA) appeared on the market in the early 90s. Only a few years later, Bruce H. Thomas developed ARQuake, the first outdoor mobile AR game on PDA [20]. The mobility offered by handheld devices, and the increased progress in terms of software, led to the spread of AR applications as well as the development of new interfaces and new technologies. In 2014, Google announced Project Tango, an Android solution for AR that combines three core technologies: depth perception, motion tracking, and area learning [21].

Since then, stand-alone AR has gradually become more common as computing power on PDAs and smartphones has increased. AR applications implemented on mobile devices were named mobile AR, or handheld mobile AR (HMAR). Such a system is, in its basic form, a mobile device with a display to show an augmentation using the appropriate software [22], with the following characteristics [23]:

- it combines real and virtual objects in a real environment;

- it is interactive, works in real time;

- it registers and aligns real and virtual objects with each other.

There are 2 key issues that need to be considered when developing MAR applications: the accuracy of user tracking and the registration of 3D models with real-world features [24]. The tracking, or the estimation of camera position, can be realized in two ways:

- marker-based tracking, which requires labels with a colored or black and white pattern;

- marker-less tracking, which uses the mobile device's GPS or image recognition systems to identify a location [25].

In the case of a $\mathrm{CH}$ application, placing markers in the scene is not practical; thus, marker-less methods are required for extracting features from the environment. These features are used for correct alignment of virtual information with real information, a process known as registration. There are two methods of registration: 
- without prior knowledge-the registration is realized 'on-line', without any prior scene knowledge;

- $\quad$ with prior knowledge-predefined patterns are taken into account from the environment in order to identify a match. An overview on the history of tracking for MAR is given in [26].

The surveys on MAR work performed in different application domains [27], or strictly related to the touristic context [28], highlight some determinants and issues that have impact on the utilization of this type of application [15]. Although MAR applications were first designed and tested in indoor environments, the advantage of portability provided by mobile devices facilitated their expansion to the outdoors. This allowed visualization of 3D models of heritage sites to be superimposed over the video stream from the outside environment [29], visualizing virtual points of interest (POIs) overlaid on top of the phone's camera view [30], or textual annotation of outdoor locations based on GPS measurements [31]. Reference [32] proposed an application for outdoor site exploration throughout different periods of time, enriching travel experiences with important historic facts. In other research papers, the authors have used MAR applications "in situ" so that the visitors were able to explore and visualize building details in an intuitive way [33], to educate students visiting an outdoor archaeological site in a game-like approach-“Oracle of Delphi app" [34], or for huge reconstructed models of heritage monuments (e.g., Roman Theatre of Byblos) [35]. A novel paradigm is proposed in [36] based on presenting user artwork, in terms of 3D models, videos, and photos, in virtual kiosks augmented on the camera view of a handheld device.

$\mathrm{AR}$ has been introduced in the $\mathrm{CH}$ sector over the last decade primarily as a useful technology for assisting visitors inside museums or in heritage sites [37-39]. It allows visitors to explore and appreciate the objects showcased by overcoming barriers in time, space, and language [40]. It also improves the learning experience in $\mathrm{CH}$ with the aid of better user interaction methods [24,41]. For instance, in [42] the information is organized in finite triplets (visual representation, context, and corresponding audiovisual content) in order to be presented in a personalized, interactive manner on users' personal mobile devices. Using AR techniques, geomatic resources were also developed, allowing the valorization of the geological heritage [43]. MAR applications can provide real-time information based on the user's preferences and context [44], and can also generate revenue or economic returns [45]. A thorough review of AR applications for $\mathrm{CH}$ is provided in [46].

Moreover, AR technologies have proven their importance in the virtual reconstruction of historical monuments, having the potential to provide a new approach to the past by reproducing on-site historical experiences [13]. In the last decade, many objects, monuments, or historical sites were reconstructed into digital formats. The significance of reconstruction is to preserve, protect, and interpret culture and history [4], and to bring to life elements from the past [47,48]. According to [49], every two years the digital heritage is doubling in size and is expected to grow tenfold between 2013 and 2020. While digital heritage is primarily concerned with preservation of $\mathrm{CH}$, virtual heritage $(\mathrm{VH})$ involves the synthesis, conservation, reproduction, representation, digital reprocessing, and display [50] of monuments, artifacts, buildings, and culture, aiming to be more open to global audiences [11]. $\mathrm{CH}$ does not end with objects and collections. It also includes information such as traditions, performing arts, social practices, rituals, festive events, activities related to nature and the universe, or skills to produce traditional crafts [51]. According to UNESCO this is the intangible $\mathrm{CH}$, and in order to be celebrated and contemplated more easily, requires the creation of specific conditions to ensure its viability when it is materialized in the form of a media resource [2].

However, the development of applications that targets reactivation of $\mathrm{CH}$ in local citizens remains a challenge [52]. In this sense, it is of the utmost importance to take into account the process of evaluation of digital cultural resources. Digital resources are a combination of cultural resources that are created using computer and multimedia technologies. They can be accessed and used in digital form [53].

Given their diversity, evaluation is not a simple process. In this paper we focus only on the evaluation of MAR applications. These should be carefully designed and improved based on user 
feedback [54]. An important component, which is studied in several papers, is the usability of the application. Relying on five usability principles developed in [55], and on a compilation of heuristic evaluation checklists for mobile interfaces proposed in [56], an MAR application was evaluated in [57] in terms of usability and user expectations. Usability was evaluated in [58] using four different methods. In [52] a methodological framework was proposed, which allowed developers to categorize the type of $\mathrm{CH}$ application and to determine which resources should be used. Santos designed a questionnaire for usability evaluation (HARUS), which was composed of two sub-questionnaires, namely the comprehensibility scale and the manipulability scale [59].

Tourist requirements for the development of mobile AR applications were investigated in [60], concluding that tourists are increasingly expecting methods to access information instantly. Other components of experience with AR applications in public were examined in [61], including designing interface features, augmentation features, and so on. Good results after an evaluation of user experience in a mobile AR tourist guide, in terms of ease-of-use and intuitiveness, were obtained in [62]. Users' perceptions and experiences were measured by applying a modified technology acceptance model (TAM) in [63]. Immersion, seen as a form of cognitive and emotional absorption in AR settings, was studied in [64].

In conclusion, there are various studies regarding augmented reality applications in the $\mathrm{CH}$ area. Most of them show that the use of new technologies creates innovative and attractive options that increases the users' interest in learning more about $\mathrm{CH}$. However, there are just a few that try to target people from more than one country. Project Tango represents a high-end technology that provides stable and reliable motion tracking. Based on this technology, we've developed an application and assessed its adoption using a questionnaire adapted from [54] and [65], which characterizes the following four subjective parameters: perceived comprehensibility, perceived manipulability, perceived enjoyment, and perceived usefulness. To the best of our knowledge, this is one of the most extensive user studies in AR conducted in outdoor environments.

\section{Materials and Methods}

\subsection{Mobile Augmented Reality (MAR) Setup}

The AR application presented in this paper was developed with the aim of bringing to life specific moments from Ovid's life. It was designed for the Lenovo Phab 2 Pro phablet (which incorporates the Google Tango technology). At the time of the research, this was the only Tango-enabled device available on the market. Phab 2 Pro used a Qualcomm Snapdragon 652 processor, 4 GB of RAM, and 64 GB storage. It used specialized Tango-related sensors-a fisheye camera that can handle the motion tracking, and an infrared depth sensor that used the "time-of-flight" principle to corroborate data with the video stream outputted by the camera [66]. Google Tango incorporates three core components:

1. Motion tracking-Tango implements visual-inertial odometry that is used to estimate the trajectory of the device (i.e., its position in the scene relative to the starting point). The inertial sensors of the mobile device are used to provide data regarding the acceleration and rotation of the device.

2. Area learning-This allows the ability to see and remember certain visual features of a physical space (edges, corners, unique features). Thus, the device is able to "recognize" the area. The motion tracking alone can be affected by "drift", which is caused by the integration of inertial data. Area learning improves the accuracy of the trajectory (through a process called "drift correction") and allows a Tango device to perform "localization" (orient and position itself when it recognizes a previously learned area).

3. Depth perception-Tango-enabled devices can understand what is the distance to any object in the real world. A common use is to obtain point clouds of scanned objects in real time. 
The AR application that was developed by our team was called OvidAR and used motion tracking and area learning. It required a map in order to start the 3D scene. The workflow for using a Google Tango-enabled device is presented in Figure 2. The area learning application was a demo provided by Tango Project and can only be used to create new area descriptions. The OvidAR application started the 3D scene if there was a previously saved map and if it detected the key visual features that were saved in the area's description file.

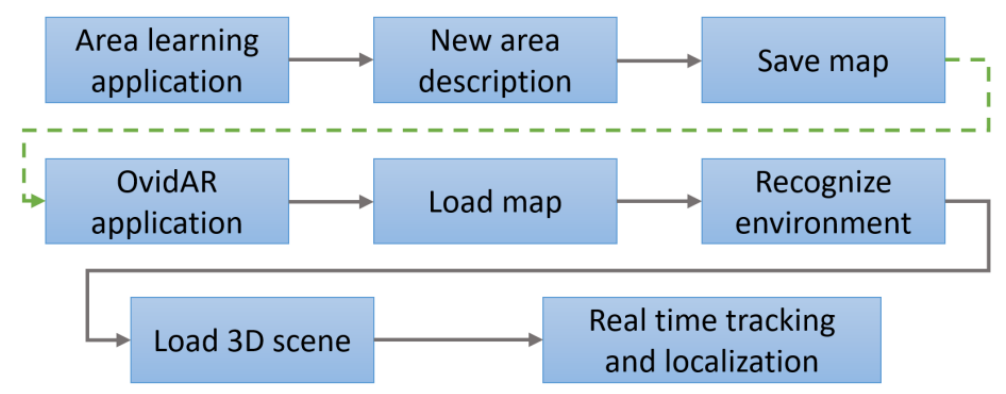

Figure 2. Proposed augmented reality workflow using Project Tango.

Real-time tracking and localization ensures that the user is immersed in the scene. Various animations of the 3D versions of Ovid created a feeling of interaction. Another key element that enhances the experience is the sound, specifically the reverberation zones that distort the audio depending on the location of the audio listener in the reverb zone.

The developed application can run only on Tango-compatible devices. There were some devices that supported Google Tango, like Asus Zenfone AR, but now the project is closed. Google introduced a new AR platform, known as ARCore. Users can still develop AR application using Tango technology, but there are no other releases or provided support.

\subsection{D Reconstruction and Application Development}

A preliminary stage of the work was the design of the 3D objects that served as content for the MAR application. For this purpose, we used historical references for the reconstruction of archaeological artifacts discovered in Dobrogea, a historical region situated in the southeast part of Romania, enhanced with animated elements. The ruins of a Roman house situated in an archeological site in the center of Constanta, known as Tomis in the past, were photographed and measured in order to create a 3D object. Photogrammetry allowed us to obtain a good representation of the walls, which we used as a base for the house. A 3D model of an ancient Roman house was designed using Autodesk 3D Studio Max software, version 2016 (Autodesk, California, USA) [67] (Figure 3). Local experts from the Museum of Archeology from Constanta provided information regarding the design of the house, more specifically, how the roof and windows should look in order to accurately present a building from that period of time.

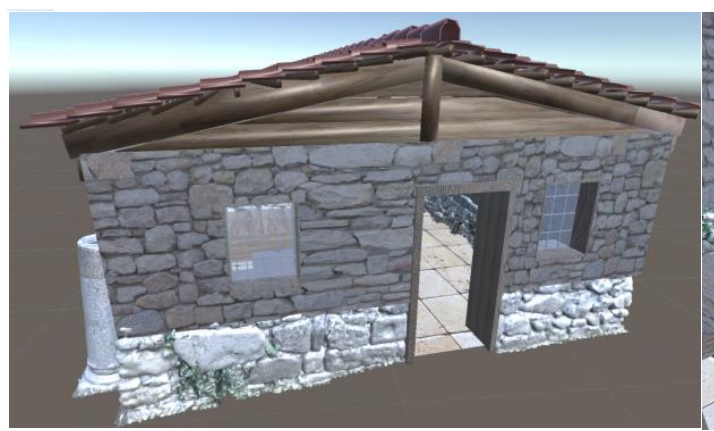

(a)

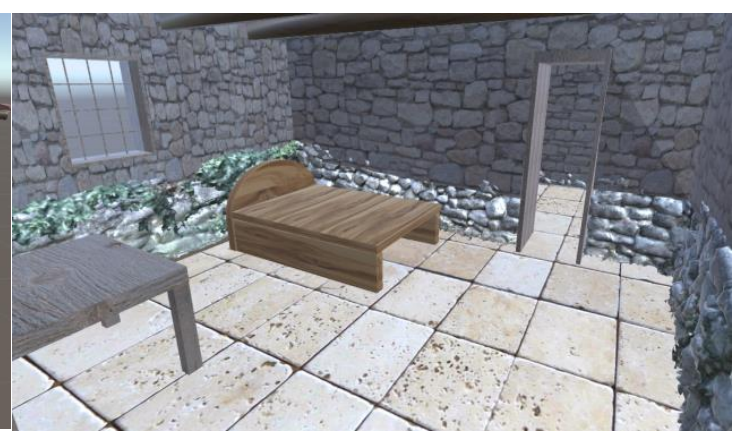

(b)

Figure 3. The 3D Roman house: (a) Outdoor view; (b) Indoor view. 
The virtual 3D character of Ovid included animations and an audio source to play the poem. Visitors used the Lenovo phablet to explore the inside and outside of the Roman house, observe the gestures of Ovid while he recited his own poem, or when he sat at the table writing a poem. If someone passed by or stood next to the virtual character, the device displayed both that person and Ovid on the screen, as in real life.

Ovid's 3D models, as child, adult in Rome, and elder in Tomis, were obtained using MakeHuman, version 1.1.0 [68] and Blender, version 2.77a (Blender Foundation, Amsterdam, Netherlands) [69], which are free, open-source software. They were animated using Adobe Mixamo [70]. The characters were designed based on the historical figure of Ovid. The selected animations corresponded to activities such as walking, sitting, writing, and idle behaviors. These models were integrated in the MAR application using Unity software, version 5.2.5 (Unity Technologies, San Francisco, USA) [71]. In Figure 4 is presented the development process of Ovid3D.

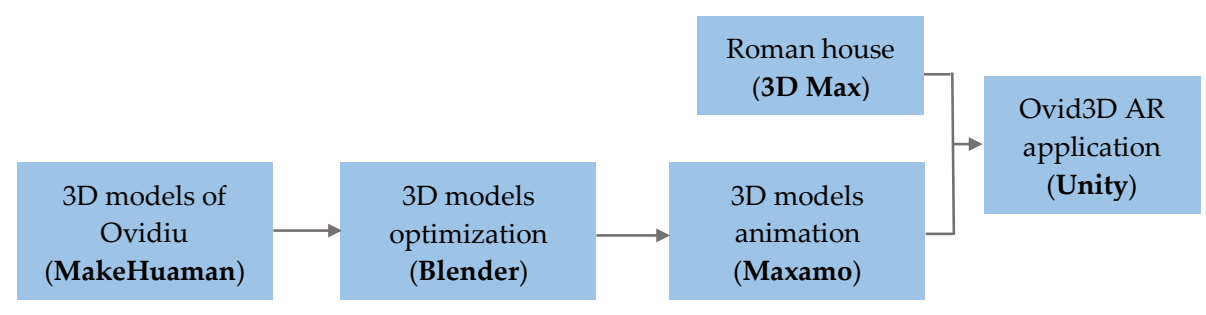

Figure 4. Development stages of Ovid3D.

\subsection{Research Method}

For the purpose of this study, several locations were selected to perform the experiment. The reason for choosing these specific places was that we wanted to present the application in cities where there was a greater possibility that tourists or residents have heard of the poet Ovid. As mentioned above, the three locations were the following:

- Constanta, Romania-In an archeological site of ancient Tomis, near the cathedral of the Apostles Saint Peter and Saint Paul;

- Rome, Italy-At the south part of Piazza de Colosseo, near Colosseum, the famous Roman amphitheater located in the center of the city;

- Sulmona, Italy-A historic town located in the province of L'Aquila in Abruzzo. The experiment took place in one of the city's main squares, Piazza XX Settembre, which is adjacent to the main street, Corso Ovidio, and very close to Piazza Garibaldi.

Not only was the location different, but also the content of the application was slightly different. For instance, in Constanta the virtual building was placed on top of the ruins of a real ancient Roman house. By doing so, users had a more realistic experience when navigating inside and outside the house (Figure 5a). This version of Ovid was reciting a short part of the poem "Sorrows", in which he expresses his complaints and fears regarding the place where he was exiled. The animated virtual model of Ovid writing at a table was located in the last room of the house, and is presented in Figure $5 \mathrm{~b}$.

In Rome, the application was similar, except that Ovid could be seen in Roman clothes, walking through the square (Figure 5c) while reciting a small part of his work The Metamorphoses, Book I-Fable 1. The Roman poet spent his childhood in Sulmona; as such, we decided to use a child version of Ovid. In this scenario, Ovid was walking outside the house, while in the background users could hear a poem recited by a child in an old Italian dialect (Figure $5 d$ ).

Therefore, there were three different applications, with different scenarios and audio content heard in the background. Each application build in Unity contained a scene with one or two characters and some objects, as follows: 
- For Sulmona, the scenario featured a Roman house, the child version of Ovid walking in circles near the house, and a child voice that recited the poem "Metamorphoses", Fable I in old Italian language. There were also some objects around the house, such as marble columns or barrels. The poem can be heard in a loop, and the animation of the child created with Mixamo repeated itself after $30 \mathrm{~s}$. The time needed to discover the whole MAR scene was roughly $150 \mathrm{~s}$, depending on the pace of the participants.

- For Rome, the application showcased a Roman house with two rooms and different pieces of furniture. The adult version of Ovid was walking in front of the house in a 15-second animation loop, and as audio content, the "Metamorphoses" narrative poem was recited by an adult voice. To discover the entire MAR scene it took around $110 \mathrm{~s}$.

- For Constanta, the scene was comprised of a Roman house and two versions of elder Ovid: one moving around the house and one writing at the table located in the second room of the house. In the background, users could hear a voice reciting Ovid's poem "Sorrows". Around $150 \mathrm{~s}$ were needed to discover the whole MAR scene.

A survey was performed following the same procedure in all locations. Participants that agreed to take part in the experiment received a verbal introduction about the purpose of the experiment and a short tutorial regarding the usage of the AR application. They received the Lenovo phablet with the OvidAR application, after which they were allowed to explore the 3D scene as much as they wanted (each participant used the app between 4 and $12 \mathrm{~min}$ ). After the experiment, participants completed a questionnaire in order to provide feedback on the experience they had using the application.

From the previous literature regarding the evaluation of MAR applications, we adopted four measurement items: perceived comprehensibility, perceived manipulability [59], perceived enjoyment, and perceived usefulness [65].

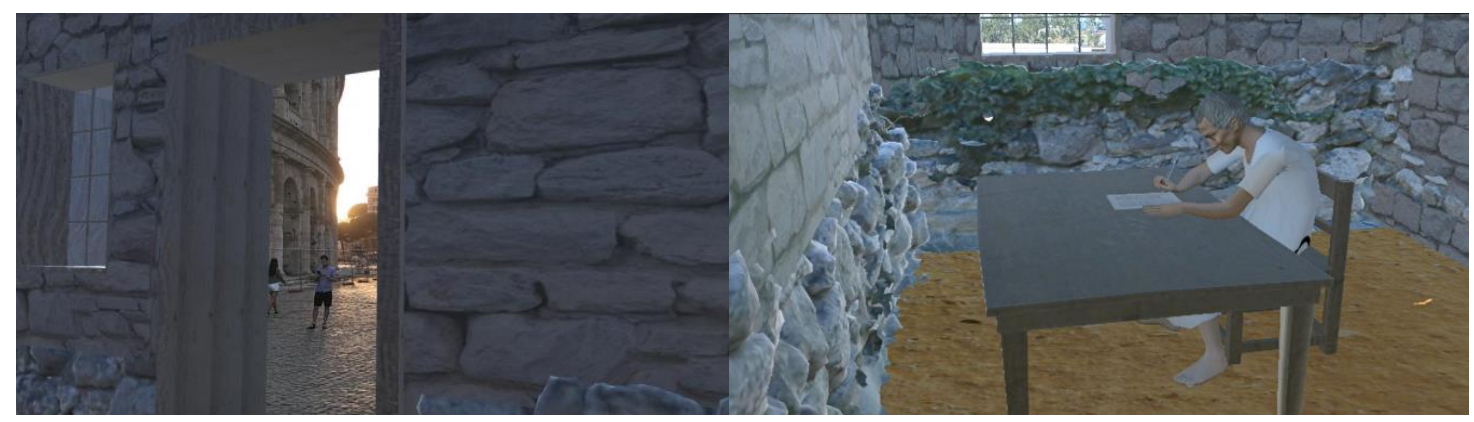

(a)

(b)

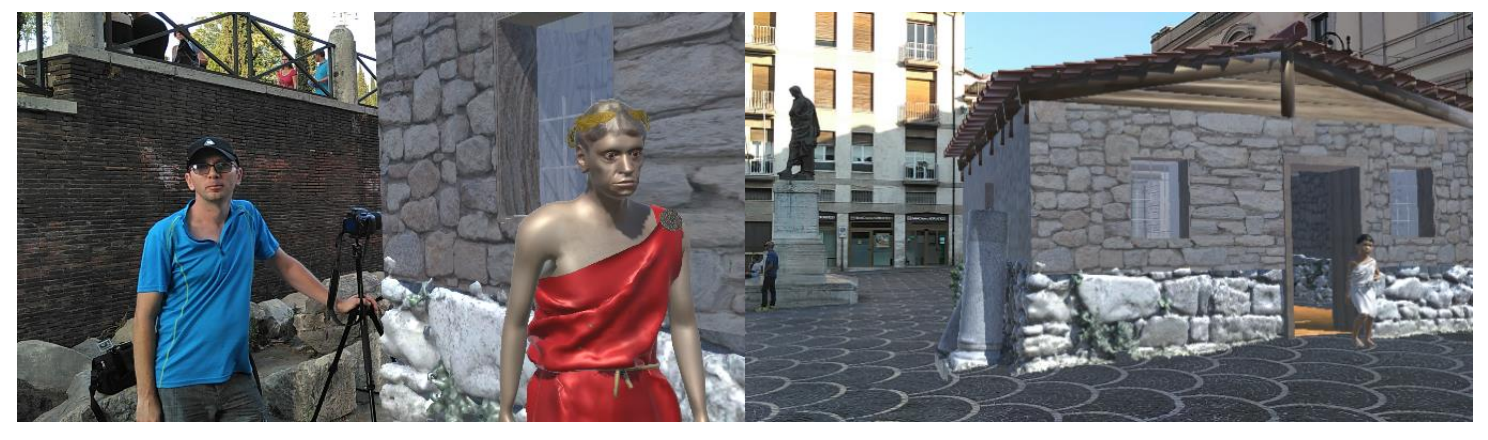

(c)

(d)

Figure 5. Photos taken during the experiments—screenshots taken in different places: (a) user looking from the inside of the house, in Rome; (b) user looking at Ovid writing at his table, in Constanta; (c) user exploring the outside of the house, in Rome; (d) user exploring the outside of Ovid's home from childhood, in Piazza XX Settembre, Sulmona. 


\subsection{Participants}

Participants included citizens and tourists that showed interest in trying a mobile AR application. A total of 63 subjects, 37 males and 26 females, aged between 17 and 62 (mean = 33.8, SD = 11.1) got the opportunity to try the application. Approximately $1 / 3$ of the respondents were between 20 and 29 years old $(34.9 \%)$, and another $1 / 3$ were between 30 and 39 years old $(33.3 \%)$. Participants were asked to rate their usage of mobile devices on a Likert-type scale (from 1 = "never use a mobile device" to 7 = "daily use of mobile devices") and if they have ever previously used an AR application. Each of them used a smartphone or tablet almost every day (mean $=5.9, \mathrm{SD}=1.1$ ) and about half of them (32) had never used or seen an AR application.

Figure 6 summarizes the demographic characteristics of the respondents. Individual characteristics for each of the places where the application was tested are briefly presented in Table 1.

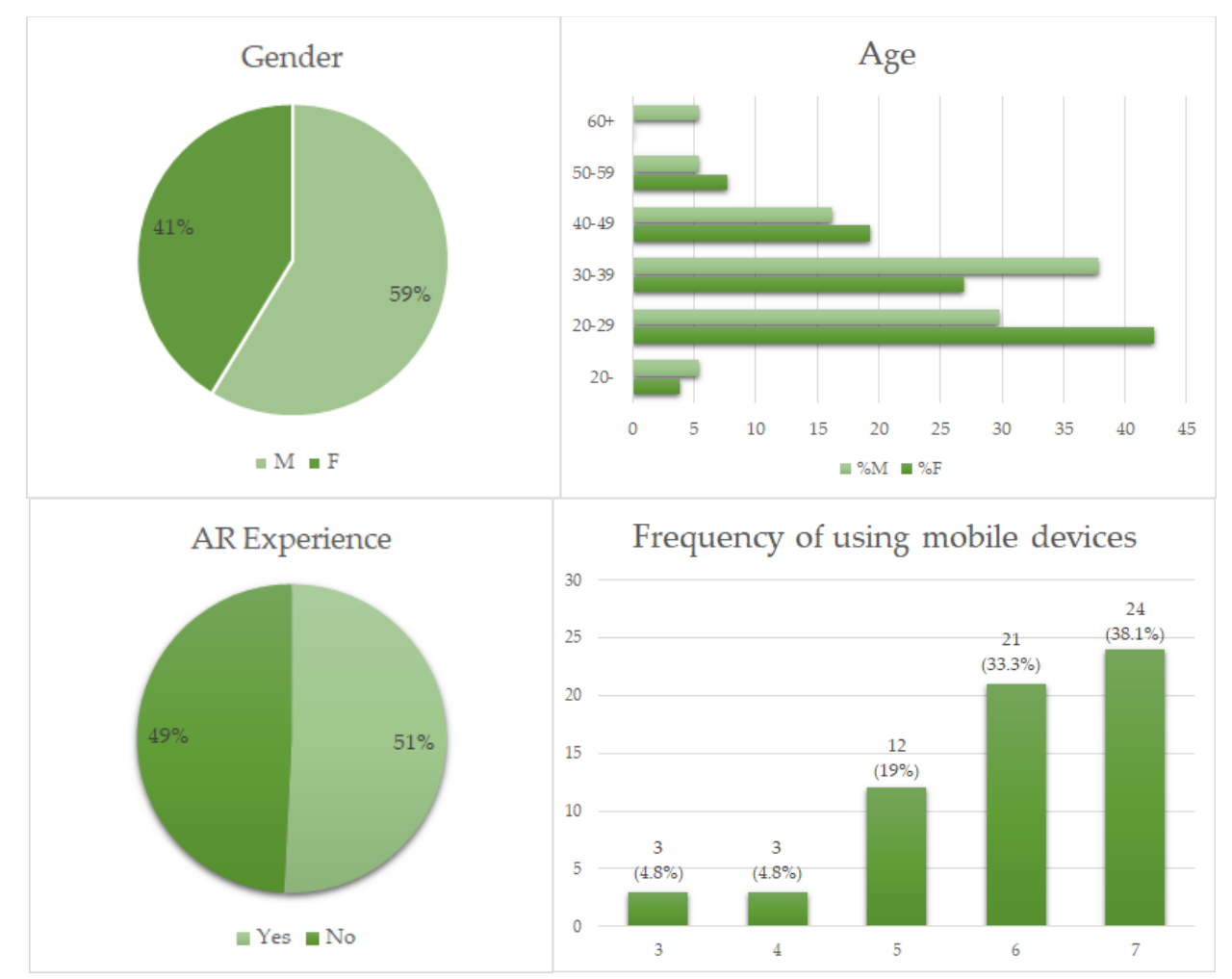

Figure 6. Showing individual variables of all the participants.

Participants that were not familiar with AR applications received a brief introduction of how AR works and how to use the OvidAR application. This was necessary to allow participants to familiarize themselves with the application so that they could evaluate the AR more accurately, even if they had never heard or seen such an application. Then, visitors were asked to use the application for approximately $5 \mathrm{~min}$ or more, and to then participate in the survey. The users who had never used AR applications were advised to evaluate OvidAR as objectively as possible, referring strictly to the application and to its content. 
The first research stage involved mostly Romanian tourists with very little AR experience, but the application was also tested and evaluated by people who had previous AR knowledge, such as the attendees of the 6th Edition of creatiVE Summer School in Virtual Environments, organized at Ovidius University of Constanta. Participants from Rome were mostly foreign tourists from Germany, USA, Canada, or Romania, but also from Italy. In Sulmona, all participants were local, Italian inhabitants of the area.

Table 1. Individual characteristics of participants for each location.

\begin{tabular}{|c|c|c|c|c|c|c|}
\hline Variables & No. & Percent (\%) & No. & Percent (\%) & No. & Percent (\%) \\
\hline & \multicolumn{2}{|c|}{ Constanța } & \multicolumn{2}{|r|}{ Rome } & \multicolumn{2}{|c|}{ Sulmona } \\
\hline \multicolumn{7}{|l|}{ Gender } \\
\hline Male & 18 & 55.0 & 12 & 63.0 & 7 & 64.0 \\
\hline Female & 15 & 45.0 & 7 & 37.0 & 4 & 36.0 \\
\hline \multicolumn{7}{|l|}{ Age } \\
\hline Under 20 & 1 & 3.03 & 1 & 5.26 & 1 & 9.09 \\
\hline $20-29$ & 11 & 33.33 & 7 & 36.84 & 4 & 36.36 \\
\hline 30-39 & 11 & 33.33 & 7 & 36.84 & 3 & 27.27 \\
\hline $40-49$ & 6 & 18.18 & 3 & 15.78 & 2 & 18.18 \\
\hline $50-59$ & 3 & 9.09 & 0 & 0.00 & 1 & 9.09 \\
\hline $60+$ & 1 & 3.03 & 1 & 5.26 & 0 & 0.00 \\
\hline \multicolumn{7}{|l|}{$\begin{array}{c}\mathrm{AR} \\
\text { experience }\end{array}$} \\
\hline Yes & 22 & 67.00 & 6 & 32.00 & 4 & 36.00 \\
\hline No & 11 & 33.00 & 13 & 68.00 & 7 & 64.00 \\
\hline
\end{tabular}

\subsection{Questionnaire Design}

The measurement items of the proposed questionnaire (22 in total) are summarized in Table 2 by each construct: perceived comprehensibility (eight items), perceived manipulability (six items), perceived enjoyment (four items), and perceived usefulness (four items). The participants had absolute freedom to fill the questionnaire to their own discretion.

The questionnaire was divided into three parts:

- The first section intended to collect some individual variables such as age and gender, participants degree of familiarity with mobile devices and AR applications, and if they had knowledge of who Ovid was;

- The second section (statements 1 to 14 ) intended to evaluate the usability of the application using the handheld augmented reality usability scale (HARUS) [54]. The HARUS questionnaire had been developed for evaluating the comprehensibility and manipulability of MAR applications. The HARUS questionnaire contained eight statements for the comprehensibility scale and eight statements for the manipulability scale, but we decided to remove two of the manipulability questions ("I found it easy to input information through the application", "I think the operation of this application is simple and uncomplicated") because they were not relevant to the evaluation of the proposed application;

- The last section (statements 15 to 22) aimed to assess the perceived enjoyment and usefulness of the application. The questions have been extracted from the questionnaires proposed in [65]. QU 3 and QU 4 was added in order to evaluate the feature that allowed users to hear audio content. 
Table 2. Questionnaire items.

\begin{tabular}{cccl}
\hline No. & Construct & Abbreviation & \\
\hline 1 & Comprehensibility & QC 1 & The interaction with this application requires a lot of mental effort \\
2 & QC 2 & The amount of information displayed on screen was appropriate \\
3 & QC 3 & The information displayed on screen was difficult to read \\
4 & QC 4 & The information display was responding fast enough \\
5 & QC 5 & The information displayed on screen was confusing \\
6 & QC 6 & The display was flickering too much \\
7 & QC 7 & The information displayed on screen was consistent \\
8 & & QC 8 & The position error of the information displayed on the screen was negligible or null \\
\hline 9 & Manipulability & QM 1 & Interaction with this application requires a lot of body muscle effort \\
10 & & QM 2 & Using the application was comfortable for my arms and hands \\
11 & & QM 3 & The device was difficult to hold while operating the application \\
12 & & QM 4 & My arm or hand became tired after using the application \\
13 & QM 5 & I felt that I was losing grip and dropping the device at some point \\
14 & & QM 6 & The application is easy to control \\
\hline 15 & Enjoyment & QE 1 & I liked to use this application \\
16 & & QE 2 & I found using the application unpleasant \\
17 & & QE 3 & I found using the application exciting \\
18 & & QE 4 & I found the application boring \\
\hline 19 & Usefulness & QU 1 & Using the application, I could quickly and easily find historical pictures and information \\
20 & & QU 2 & Using the application, I have improved my knowledge about the life of Ovid \\
21 & & QU 3 & Listening to a poem of Ovid and was useful and interesting \\
22 & & QU 4 & Listening to Ovid in some circumstances was useful and interesting \\
\hline
\end{tabular}

All the questions used a 7-point Likert scale, ranging from 1—“strongly disagree", to 7-"strongly agree". Depending on the time availability, users were asked to fill in the questionnaire on site, or instead, access a survey link sent to their e-mail to be completed at a later time. Out of the 63 questionnaires collected, 21 were completed online and 2 incomplete questionnaires were eliminated. A total of 61 questionnaires were used for this study (96.82\%).

The online survey questionnaire was developed in English, and the paper-based questionnaire was translated into Romanian and Italian for participants who had difficulties understanding English.

\section{Results}

Responses were put together to obtain a value for each of the four constructs defined by the questionnaire: comprehensibility, manipulability, enjoyment, and usefulness. The questionnaire contained both positive and negative worded items. For the negatively formulated questions, we first reversed the results in order to have the same scale. We chose to alternate positive and negative items. In this way, the user may be more careful when completing the questionnaire, and the answer was, thus, more relevant for the survey. After that, the scores were converted to a range of 0 to 6 . All the values were then summed, and the sum was mapped to a range of 0 to 100 . This method of data aggregation was done according to the instructions from the original HARUS questionnaire assessment [54].

Figures A1-A3 from Appendix A show the obtained scores for each of the questions for the three experiments, represented as box charts. In each figure, mean, median, interquartile values, whiskers, and outliers were reported.

For validating our measurement model, we evaluated reliability and sampling adequacy. Reliability was assessed by calculating Cronbach's $\alpha$, and the proportion of variance was assessed by the Kaiser-Meyer-Olkin index. Each of the measures exceeded the recommended threshold (Cronbach's alpha $=0.902$, Kaiser-Meyer-Olkin $=0.796$ ).

When participants were asked: "Do you have any knowledge of who Ovid is?", the majority of them answered "Yes" from all three locations. Results showed that Ovid was known by $95 \%$ of the participants in Sulmona, 91\% of the participants from Rome admitted to have heard of Ovid, while only $73 \%$ of the participants in Constanta heard of him. The values obtained for each question for all the users are displayed in Figure 7. 


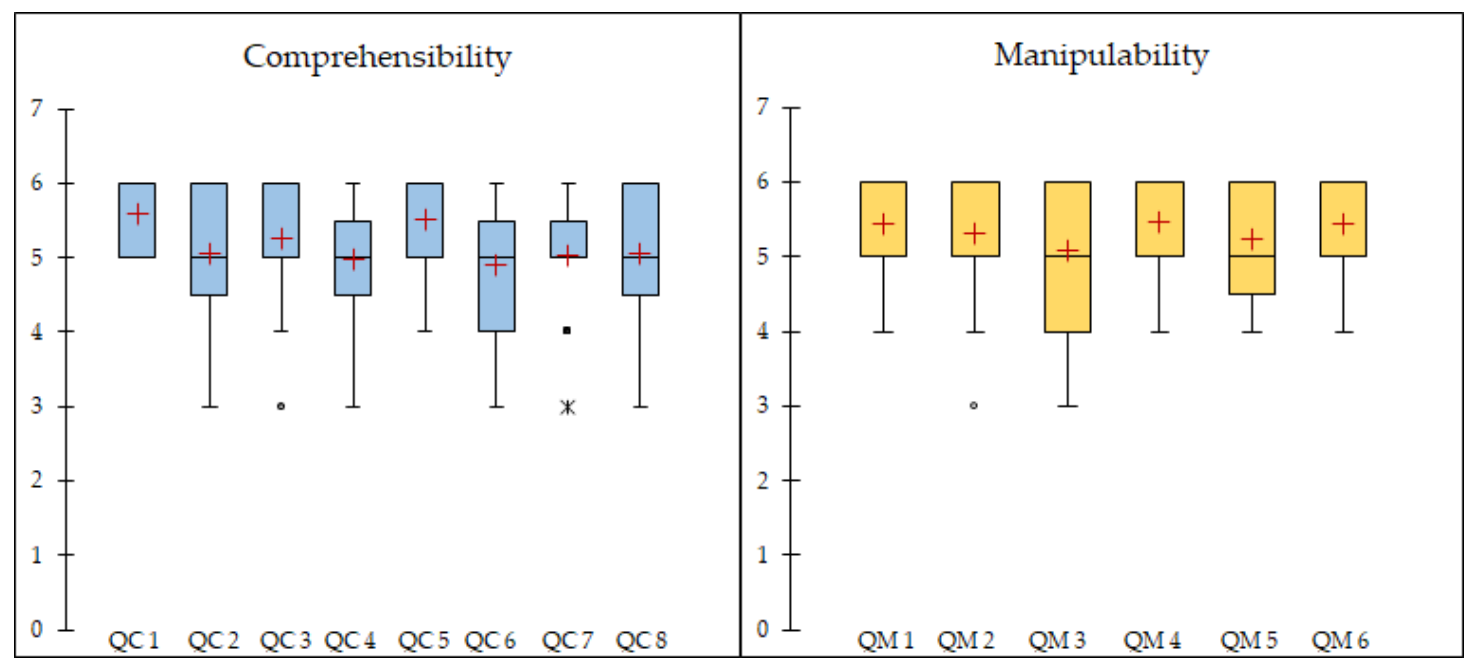

(a)

(b)

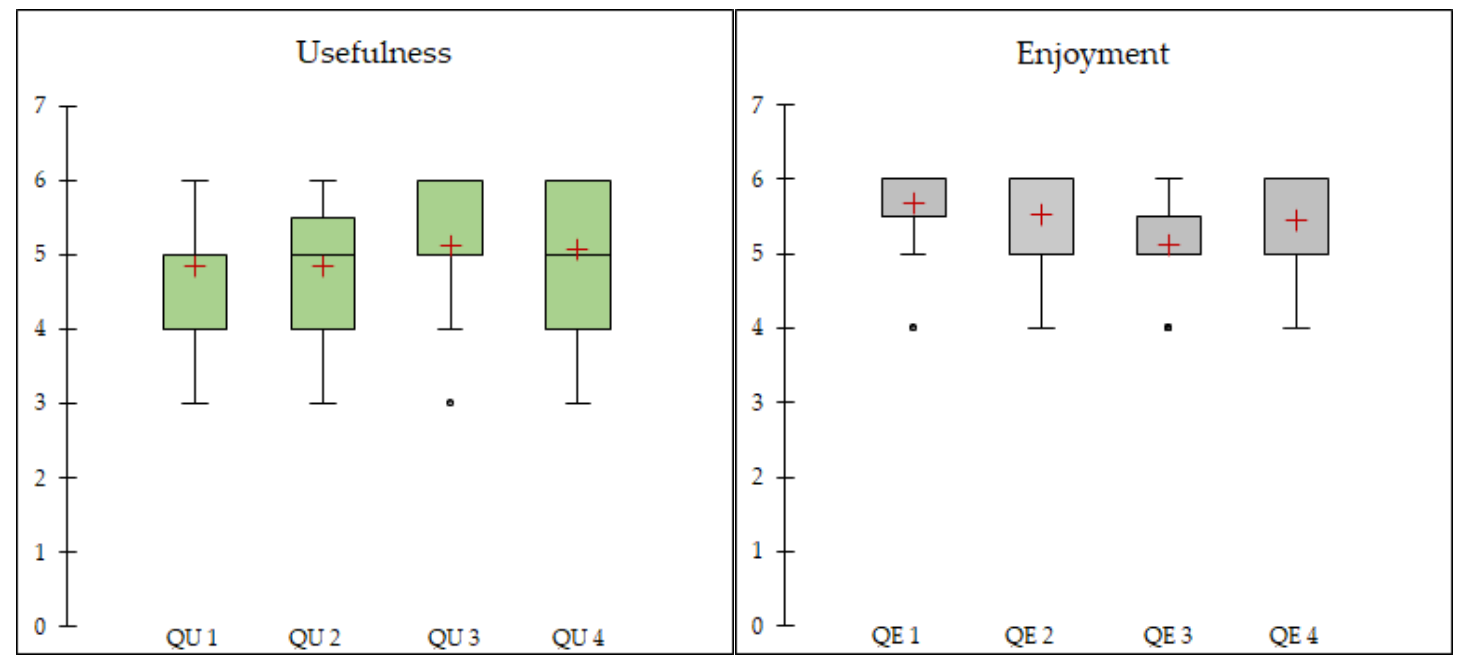

(c)

(d)

Figure 7. Boxplots showing the outcomes for the questions, grouped into the four constructs.

The values for each construct—comprehensibility (mean $=91.06$; SD $=4.46)$, manipulability $($ mean $=93.81 ; \mathrm{SD}=2.66)$, enjoyment $($ mean $=95.88 ; \mathrm{SD}=4.11)$ and usefulness $($ mean = 87.57; $\mathrm{SD}=2.61$ ) -are reported in Figure 8, separately for each experiment, and overall. The vertical axis is displayed from 80 to 105 to make the results visible.

At the end of the experiment, some participants showed interest in learning more about AR and how it could change the way people explore and learn new things about heritage and education. 


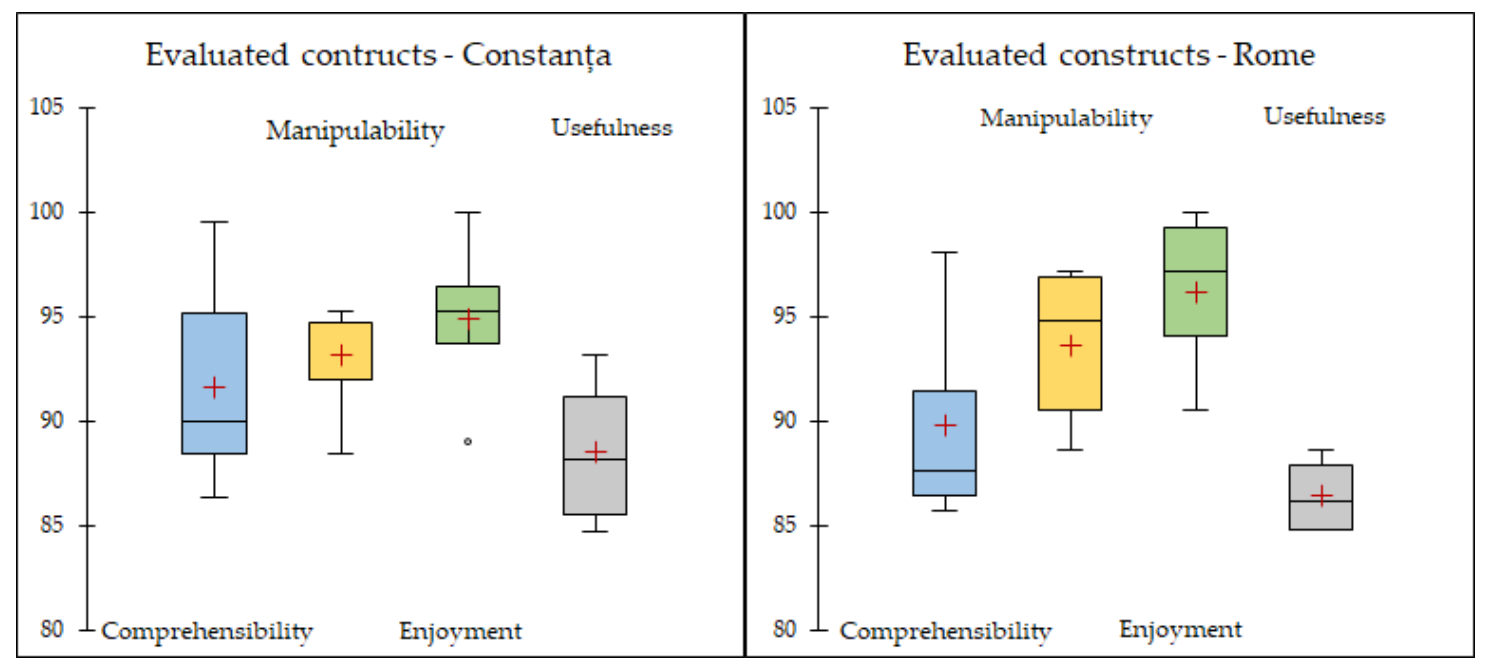

(a)

(b)

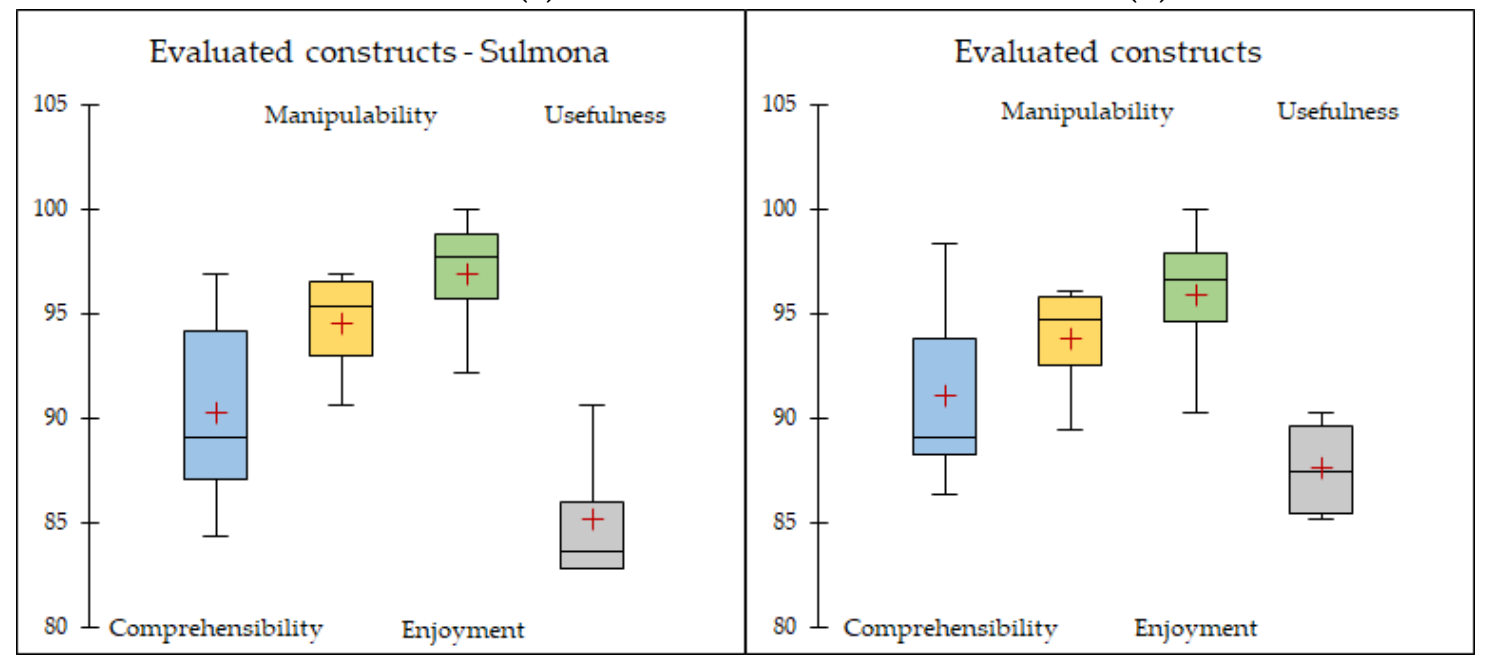

(c)

(d)

Figure 8. Boxplot showing the results for the four constructs.

\section{Findings and Discussion}

The survey was performed to identify users' appreciation for mobile AR applications in the context of urban heritage. The following sections discuss the results from the survey, for each of the four parameters that were evaluated.

\subsection{Comprehensibility}

The values obtained for each question of comprehensibility indicated a positive evaluation. The responses to QC1 and QC5 had a median of 6.0 and a mean over 5.5. All the others had a median of 5.0 and a mean between 4.91 and 5.27. Item QC6 received the lowest, and item QC1 obtained the highest score. This showed that the application was easy to use and it was intuitive, but there were still small stability tracking issues that determined a slight flickering of the 3D content.

At the same time, the overall values obtained from the three surveys were very similar: Constanta $($ mean $=91.58)$, Rome $($ mean $=89.76)$, and Sulmona $($ mean $=90.23)$. 


\subsection{Manipulability}

On perceived manipulability in the survey, QM4 and QM6 items had a median of 6.0 and a mean over 5.4. The others had a median of 5.0 and a mean between 5.08 and 5.44. While QM4 obtained the highest score, QM3 had the lowest median. The device was small, and the users did not have problems related to their arm comfort. Only small difficulties in holding the device while operating the application were reported.

Similar to the comprehensibility construct, very close values were obtained for all the experiments for the manipulability construct: Constanta (mean =93.16), Rome (mean =93.65), and Sulmona (mean $=94.53)$.

\subsection{Enjoyment}

For perceiving enjoyment, only QE3 had a median of 5.0, while the other three items had a median of 6.0. The mean ranged from 5.13 to 5.68. For this construct we obtained the highest values. QE1 achieved the highest score from all the questions that were proposed in the survey. The users liked to use the application. Good results were also obtained for QE3, which indicated that the objective set at the beginning was met. Only eight participants rated 5 in the Likert-scale for this question, and the others rated it 6 and 7.

The values obtained for this construct were: Constanta (mean $=94.87)$, Rome (mean $=96.19)$, and Sulmona $($ mean $=96.88)$.

\subsection{Usefulness}

On perceived usefulness, all four items had a median of 5.0 and a mean between 4.84 and 5.12. Item QU1 had the lowest average score. Some users suggested that the application might be improved with text to better reflect its purpose and to have more historical information about Ovid. Better scores were obtained for the items related to audio content, i.e., when Ovid's poem was heard in the background.

Perceived usefulness achieved the lowest score in the three cases: Constanta (mean $=88.55$ ), Rome $($ mean $=86.43)$, and Sulmona $($ mean $=85.16)$.

Usefulness was the area of the survey where the users had the most variable results. The standard deviation ranged from 0.81 to 0.90 . However, the highest value for standard deviation was obtained for item QM3 $(\mathrm{SD}=0.94)$.

Briefly, we can conclude that participants enjoyed using the application and were mostly satisfied with its content. Although some historical data were missing, the application was easy to use, it was useful, and it confirmed the fact that the development of new interfaces for promoting $\mathrm{CH}$ is a sustainable action well-received by the public. Relevant photos and screenshots from the experiments are presented in Figure 9.

In Figure 9a2 the modelled house of Ovid is presented, placed on the top of the ruins of the real ancient house from Constanta. Figure $9 \mathrm{c}$ represents another modelled house, and the child version of Ovid walking.

The technology allowed registration of the model in different places accessible to tourists. It took into account their orientation, and adapted to their viewpoint. A wide variety of tourists can use the device (Figure 9a1,a3,b). 


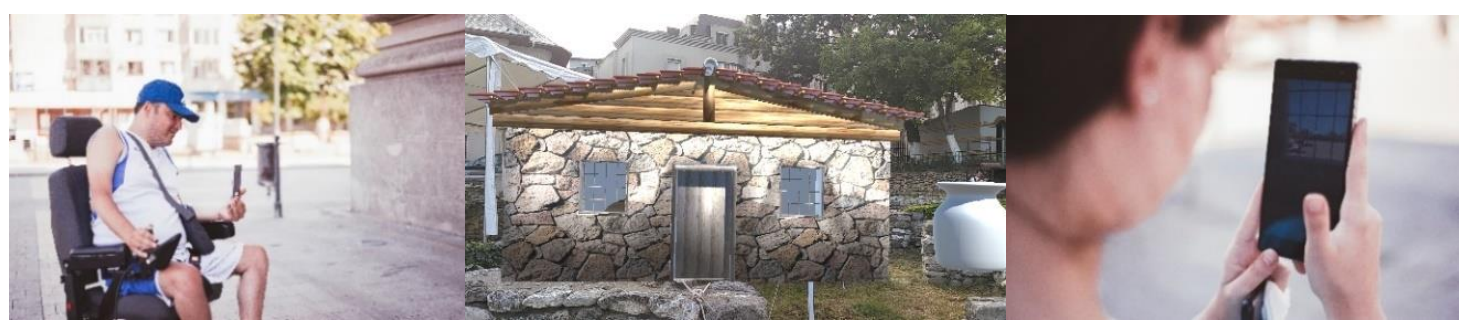

(a1)

(a2)

(a3)

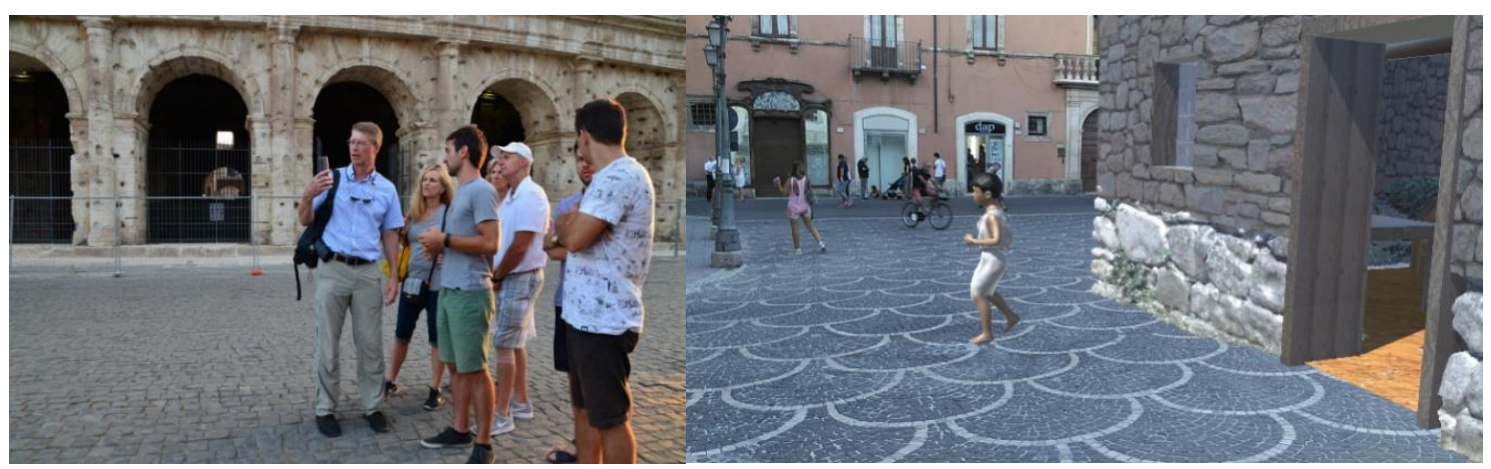

(b)

(c)

Figure 9. Mobile Augmented Reality (MAR) application used in (a) Constanta, (b) Rome, and (c) Sulmona.

\section{Conclusions}

Despite the fact that MAR applications show great potential in the $\mathrm{CH}$ area, the number of works that provide an analysis of user acceptance is relatively low. This work aimed to add value in this respect, and proposed a user study to assess participants' perception regarding the use of an MAR application with historical information related to $\mathrm{CH}$. A prototype AR application was implemented as a subject for the study, and a questionnaire was used for collecting the data. Three sessions were conducted in three different locations, with participants from several countries. The questionnaire items, other than demographic information, intended to analyze the following four constructs: comprehensibility, manipulability, enjoyment, and usefulness.

The results show that the usability of the MAR application and the interaction was considered appropriate. Good results were obtained for all four constructs that were analyzed.

It should be noted that MAR technology has proved to increase the accessibility of tourists to intangible heritage. Tango technology allows users to create and save maps of the environment that are linked to the starting point of a scene, thus making it easy for developers to create AR applications.

The application meets the proposed objectives. Most of the users agreed that OvidAR had attractive content and met the usability requirements, providing a positive experience during the interaction. AR is a technology that will be more accessible in the upcoming years, and people will be more receptive in using it. In the field of $\mathrm{CH}$, institutions and companies started to use this technology in order to provide more realistic experiences for tourists and museum visitors. In this regard, we think that AR technology represents a proper media for the sustainability of $\mathrm{CH}$ conservation and/or documentation.

Nevertheless, this study is not exhaustive. Our aim was not to obtain data that was statistically reliable, but to present a method that can be used sustainably to disseminate $\mathrm{CH}$ events at an international level. Future developments can include: improving tracking stability by fine tuning the Tango-related parameters, improving the 3D models to make them more realistic, or conducting further usability evaluations that involve more constructs and participants. That being said, we conclude that MAR could be one of the answers to various problems faced by the $\mathrm{CH}$ area in the 21st century, 
such as the lack of funding, the poor impact on cultural growth, and the weak cultural cohesion of neighboring countries.

Author Contributions: Conceptualization, R.G.B., C.-C.P. and D.-M.P.; methodology, G.D.V. and C.-C.P.; software, R.G.B. and G.D.V.; validation, D.-M.P., and M.C.; data curation, G.D.V.; writing—original draft preparation, R.G.B.; visualization, M.C.; supervision, M.D. and M.C.; project administration, M.D.

Funding: This paper is supported by European Union's Horizon 2020 research and innovation program under grant agreement No 692103, project eHERITAGE (Expanding the Research and Innovation Capacity in Cultural Heritage Virtual Reality Applications).

Acknowledgments: We also acknowledge the participants of the 6th Edition of the Summer School on Virtual Environments organized at Ovidius University of Constanta, Romania.

Conflicts of Interest: The authors declare no conflict of interest.

\section{Appendix A}

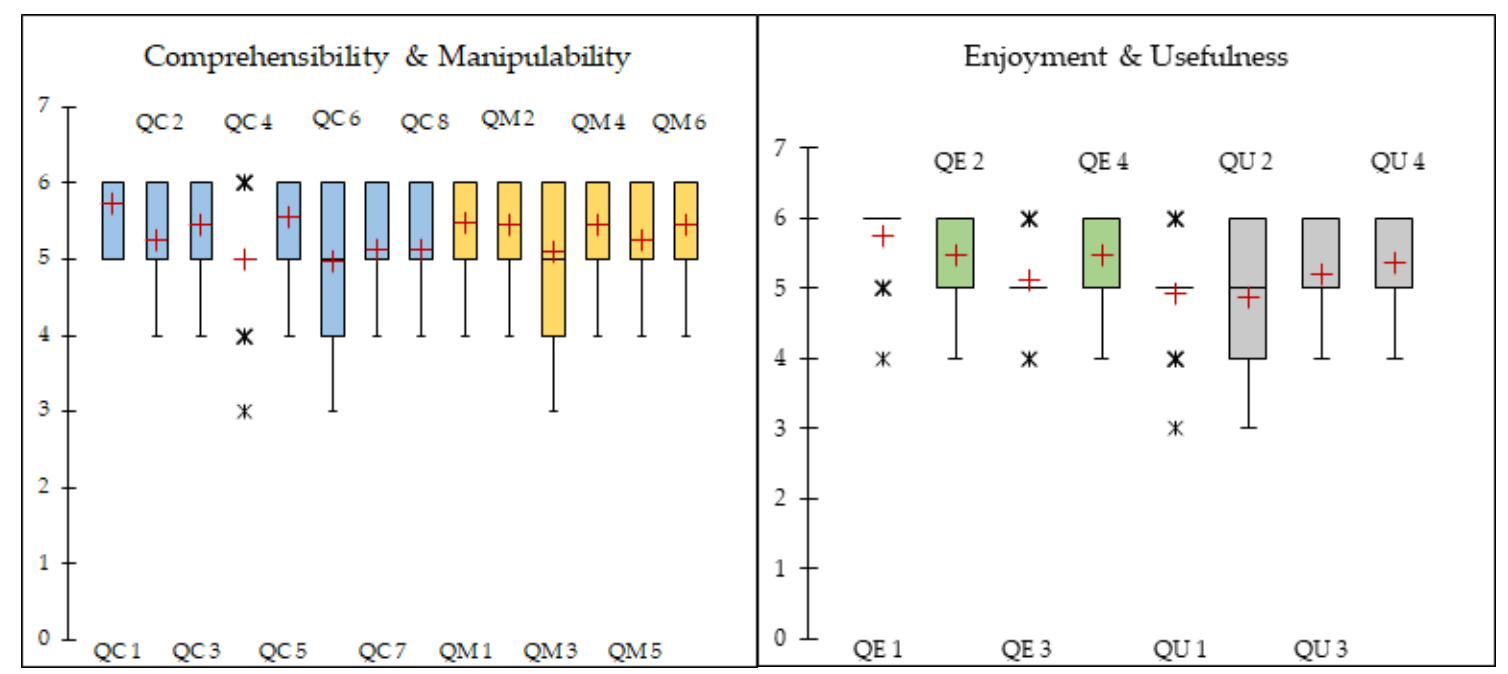

Figure A1. Boxplots showing the outcomes for the questions for the first experiment (Constanta).

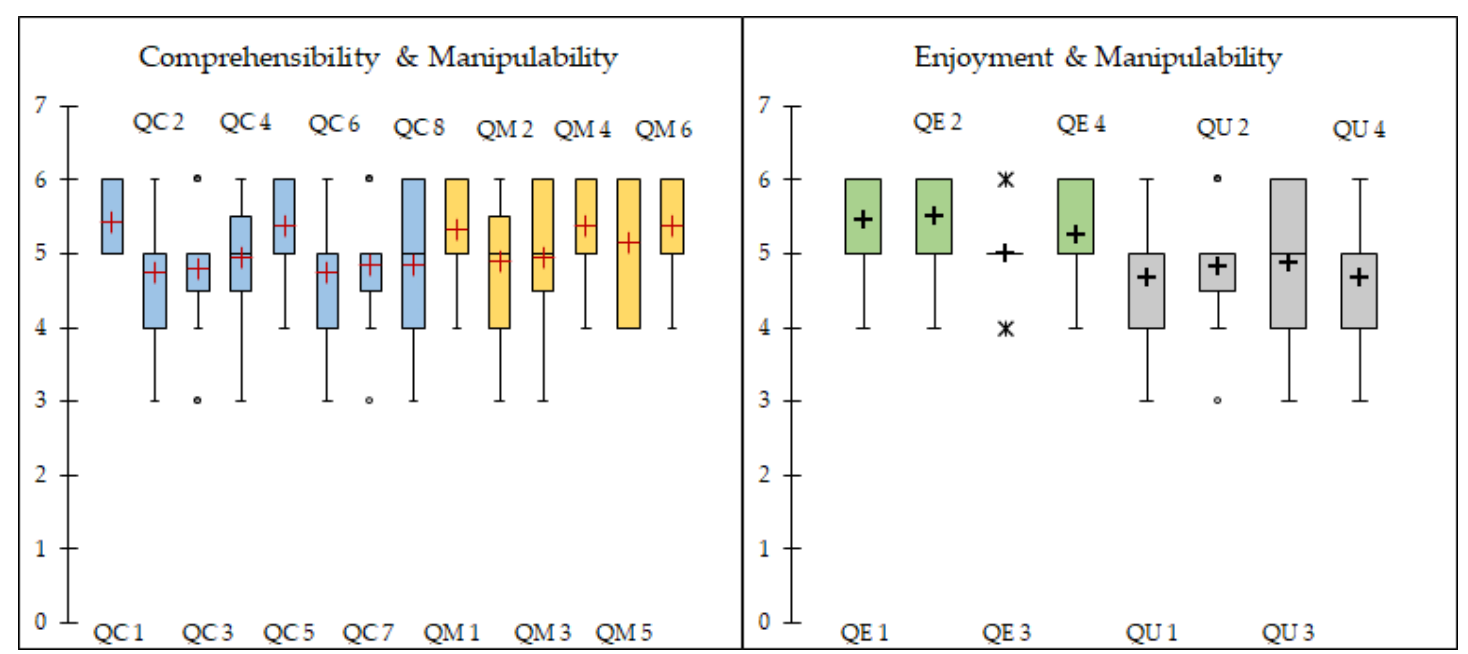

Figure A2. Boxplots showing the outcomes for the questions, for the second experiment (Rome). 


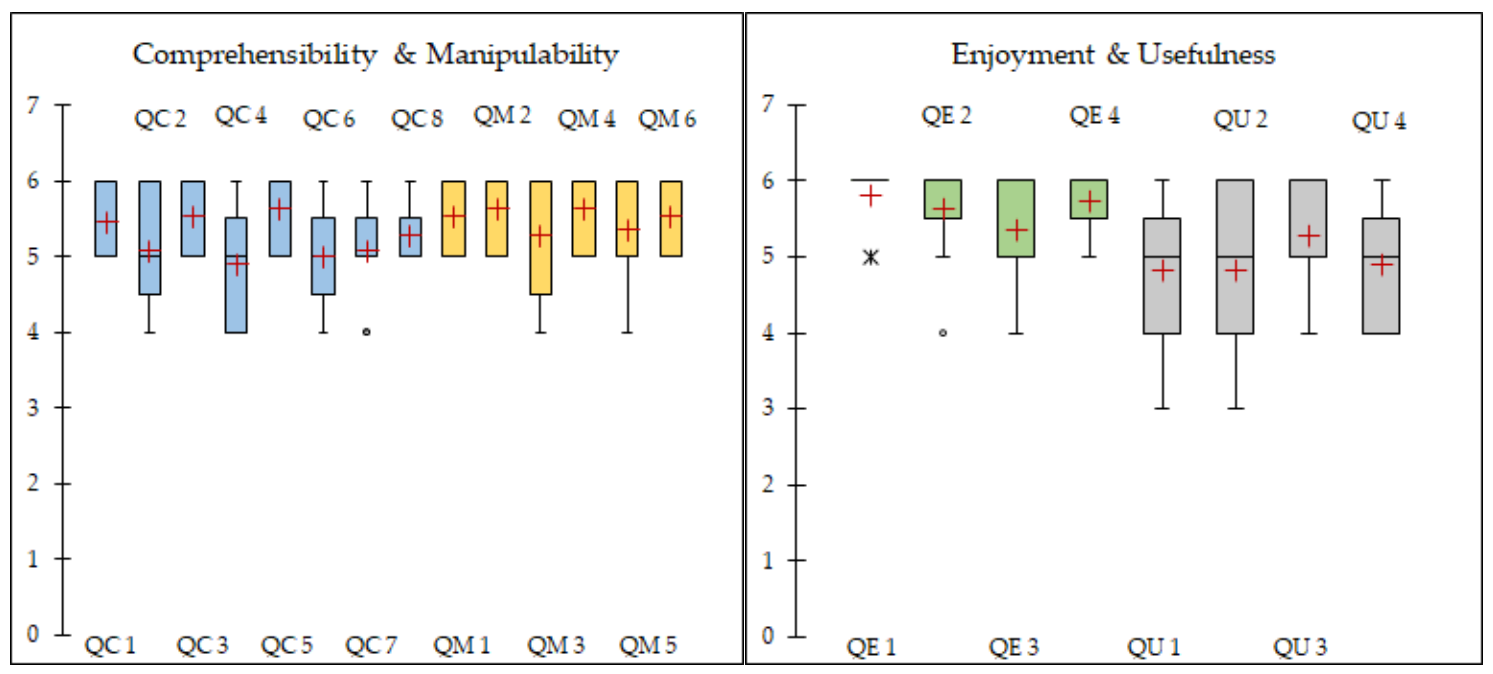

Figure A3. Boxplots showing the outcomes for the questions, for the third experiment (Sulmona).

\section{References}

1. Palombini, A. Storytelling and telling history. Towards a grammar of narratives for Cultural Heritage dissemination in the Digital Era. J. Cult. Herit. 2017, 24, 134-139. [CrossRef]

2. Madirov, E.; Absalyamova, S. The influence of Information Technologies on the Availability of Cultural Heritage. Procedia-Soc. Behav. Sci. 2015, 188, 255-258. [CrossRef]

3. Economou, M. Use and Impact of Digital in Cultural Heritage: Insights from the Scottish Network of Digital Cultural Resources Evaluation, MW17: Museums and the Web 2017, Cleveland, OH, USA, 19-22 April 2017; Museums and the Web 2017: Silver Spring, MD, USA, 2017. Available online: https:/ /mw17.mwconf.org/ paper/evaluating-impact-and-use-of-digital-cultural-resources-lessons-from-the-scotdigich-network / (accessed on 17 October 2018).

4. Creed, C.; Sivell, J.; Sear, J. Multi-Touch Tables for Exploring Heritage Content in Public Spaces. In Visual Heritage in the Digital Age; Ch'ng, E., Gaffney, V., Chapman, H., Eds.; Springer London: London, UK, 2013; pp. 67-90.

5. Thwaites, H. Digital Heritage: What Happens When We Digitize Everything? In Visual Heritage in the Digital Age; Ch'ng, E., Gaffney, V., Chapman, H., Eds.; Springer London: London, UK, 2013; pp. 327-348.

6. Malpas, J. Cultural heritage in the age of new media. In New Heritage: New Media and Cultural Heritage; Kalay, Y.E., Kvan, T., Affleck, J., Eds.; Routledge: London, UK, 2008; pp. 13-26.

7. Tahoon, D.M.A. Case Study: Pyramids and Giza Plateau cultural heritage site, Egypt. In Proceedings of the 1st BUE Annual Conference \& Exhibition (BUE ACE1), Cairo, Egypt, 7-9 November 2016. Available online: https:/ / pdfs.semanticscholar.org/5365/cce55e220ea8ee1034d5b70c170e890fabaf.pdf?_ga= 2.66583277.2118423092.1550735871-1930073487.1544169653 (accessed on 24 October 2018).

8. Boldrer, F. Recalling Ovid 2000 years later between lights and shadows: Memory and rework of a Latin poet in the Italian literature of the 20th century. In Proceedings of the Classical antiquity \& memory in 19th-20th-21st century International conference, Bonn, Germany, 28-30 September 2017. Available online: http:/ / memory.strikingly.com/blog/recalling-ovid-2-000-years-later-between-lights-and-shadows (accessed on 17 October 2018).

9. Wise, C.N. Banished to the Black Sea: Ovid's poetic transformations in Tristia 1.1. Master's Thesis, Georgetown University, Washington, DC, USA, 16 October 2014.

10. Currie, H.M. Ovid's Personality. Class. J. 1964, 59, 145-155.

11. Noh, Z.; Sunar, M.S.; Pan, Z. A Review on Augmented Reality for Virtual Heritage System. In Learning by Playing. Game-based Education System Design and Development: 4th International Conference on E-Learning and Games, Edutainment 2009, Banff, Canada, 9-11 August 2009; Springer: Berlin, Germany, 2009.

12. Wu, H.-K.; Lee, S.W.-Y.; Chang, H.-Y.; Liang, J.-C. Current status, opportunities and challenges of augmented reality in education. Comput. Educ. 2013, 62, 41-49. [CrossRef] 
13. Chung, N.; Han, H.; Joun, Y. Tourists' intention to visit a destination: The role of augmented reality (AR) application for a heritage site. Comput. Hum. Behav. 2015, 50, 588-599. [CrossRef]

14. Garrido, R.M.; Jimenez, D.V.; Baldiris, S.; Fabregat, R. "Social Heritage" Augmented Reality Application to Heritage Education. In Proceedings of the Second International Conference on Augmented and Virtual Reality, VR 2015, Lecce, Italy, 31 August-3 September 2015. Available online: https: / www.springer.com/cda/content/document/cda_downloaddocument/9783319228877-c2. pdf?SGWID=0-0-45-1524302-p177647007 (accessed on 17 September 2018).

15. Kečkeš, A.L.; Tomičić, I. Augmented Reality in Tourism-Research and Applications Overview. Interdiscip. Descr. Complex Syst. 2017, 15, 157-167. [CrossRef]

16. tom Dieck, M.C.; Jung, T.H. Value of augmented reality at cultural heritage sites: A stakeholder approach. J. Destin. Mark. Manag. 2017, 6, 110-117. [CrossRef]

17. Velázquez, F.D.C.; Méndez, G.M. Augmented Reality and Mobile Devices: A Binominal Methodological Resource for Inclusive Education (SDG 4). An Example in Secondary Education. Sustainability 2018, 10, 3446. [CrossRef]

18. Martins, J.; Gonçalves, R.; Branco, F.; Barbosa, L.; Melo, M.; Bessa, M. A multisensory virtual experience model for thematic tourism: A Port wine tourism application proposal. J. Destin. Mark. Manag. 2017, 6, 103-109. [CrossRef]

19. Berryman, D.R. Augmented reality: A review. Med Ref. Serv. Q. 2012, 31, 212-218. [CrossRef]

20. Clemens, A.; Lukas, G.; Raphael, G.; Tobias, L.; Alessandro, M.; Dieter, S.; Daniel, W. The History of Mobile Augmented Reality. Inst. for Computer Graphics and Vision, Graz University of Technology, Austria. 11 November 2015. Available online: https://arxiv.org/pdf/1505.01319.pdf (accessed on 17 September 2018).

21. Tomaštík, J.; Saloň, Š.; Tunák, D.; Chudý, F.; Kardoš, M. Tango in forests-An initial experience of the use of the new Google technology in connection with forest inventory tasks. Comput. Electron. Agric. 2017, 141, 109-117. [CrossRef]

22. Gjøsæter, T. Affordances in Mobile Augmented Reality Applications. Int. J. Interact. Mob. Technol. 2014, 8, 45-55. [CrossRef]

23. Chatzopoulos, D.; Bermejo, C.; Huang, Z.; Hui, P. Mobile Augmented Reality Survey: From Where We Are to Where We Go. Ieee Access 2017, 5, 6917-6950. [CrossRef]

24. Bostanci, E.; Kanwal, N.; Clark, A.F. Augmented reality applications for cultural heritage using Kinect. Hum.-Cent. Comput. Inf. Sci. 2015, 5, 20. [CrossRef]

25. Mota, J.M.; Ruiz-Rube, I.; Dodero, J.M.; Arnedillo-Sánchez, I. Augmented reality mobile app development for all. Comput. Electr. Eng. 2017, 65, 250-260. [CrossRef]

26. Wagner, D.; Schmalstieg, D. History and Future of Tracking for Mobile Phone Augmented Reality. In Proceedings of the 2009 International Symposium on Ubiquitous Virtual Reality, Gwangju, South Korea, 8-11 July 2009. Available online: https:/ / ieeexplore.ieee.org/iel5/5232241/5232242/05232244.pdf (accessed on 14 August 2018).

27. Mekni, M.; Lemieux, A. Augmented reality: Applications, challenges and future trends. In Proceedings of the 13th International Conference on Applied Computer and Applied Computational Science (ACACOS '14), Kuala Lumpur, Malaysia, 23-25 April 2014; pp. 205-214. Available online: https: / www.semanticscholar.org/paper/Augmented-Reality-\%3A-Applications-\%2C-Challengesand-Mekni-Lemieux/a77e78e46a0cdfdc191e732e23da3deac57fd366 (accessed on 12 September 2018).

28. Yovcheva, Z.; Buhalis, D.; Gatzidis, C. Overview of Smartphone Augmented Reality Applications for Tourism. e-Rev. Tour. Res. (Ertr) 2012, 10, 63-68.

29. Han, J.-G.; Park, K.-W.; Ban, K.-J.; Kim, E.-K. Cultural Heritage Sites Visualization System based on Outdoor Augmented Reality. Aasri Procedia 2013, 4, 64-71. [CrossRef]

30. Dünser, A.; Billinghurst, M.; Wen, J.; Lehtinen, V.; Nurminen, A. Exploring the use of handheld AR for outdoor navigation. Comput. Graph. 2012, 36, 1084-1095. [CrossRef]

31. Larabi, S. Augmented Reality for Mobile Devices: Textual Annotation of Outdoor Locations. In Augmented Reality and Virtual Reality: Empowering Human, Place and Business; Jung, T., tom Dieck, M.C., Eds.; Springer International Publishing: Manchester, UK, 2018; pp. 353-362. Available online: https:/ /link.springer.com/ chapter/10.1007/978-3-319-64027-3_24 (accessed on 13 September 2018). 
32. Duguleana, M.; Brodi, R.; Girbacia, F.; Postelnicu, C.; Machidon, O.; Carrozzino, M. Time-Travelling with Mobile Augmented Reality: A Case Study on the Piazza DeiMiracoli. In Digital Heritage. Progress in Cultural Heritage: Documentation, Preservation, and Protection: 6th International Conference, EuroMed 2016, Nicosia, Cyprus. 2016. Available online: https://link.springer.com/chapter/10.1007/978-3-319-48496-9_73 (accessed on 25 September 2018).

33. Puyuelo, M.; Higón, J.L.; Merino, L.; Contero, M. Experiencing Augmented Reality as an Accessibility Resource in the UNESCO Heritage Site Called "La Lonja", Valencia. Procedia Comput. Sci. 2013, 25, 171-178. [CrossRef]

34. Ekonomou, T.; Vosinakis, S. Mobile Augmented Reality games as an engaging tool for cultural heritage dissemination: A case study. Sci. Cult. 2018, 4, 97-107.

35. Younes, G.; Kahil, R.; Jallad, M.; Asmar, D.; Elhajj, I.; Turkiyyah, G.; Al-Harithy, H. Virtual and augmented reality for rich interaction with cultural heritage sites: A case study from the Roman Theater at Byblos. Digit. Appl. Archaeol. Cult. Herit. 2017, 5, 1-9. [CrossRef]

36. Sekhavat, Y.A. KioskAR: An Augmented Reality Game as a New Business Model to Present Artworks. Int. J. Comput. Games Technol. 2016, 2016, 7690754. Available online: https:/ /www.hindawi.com/journals/ijcgt/ 2016/7690754/ (accessed on 30 July 2018). [CrossRef]

37. Hammady, R.; Ma, M.; Temple, N. Augmented Reality and Gamification in Heritage Museums. In Serious Games: Second Joint International Conference, JCSG 2016, Brisbane, QLD, Australia, 26-27 September 2016; Springer International Publishing: Manchester, UK, 2016; pp. 181-187.

38. Madsen, J.B.; Madsen, C.B. Handheld Visual Representation of a Castle Chapel Ruin. J. Comput. Cult. Herit 2015, 9, 1-18. [CrossRef]

39. Pedersen, I.; Gale, N.; Mirza-Babaei, P.; Reid, S. More than Meets the Eye: The Benefits of Augmented Reality and Holographic Displays for Digital Cultural Heritage. J. Comput. Cult. Herit. 2017, 10, 1-15. [CrossRef]

40. Chung, N.; Lee, H.; Kim, J.-Y.; Koo, C. The Role of Augmented Reality for Experience-Influenced Environments: The Case of Cultural Heritage Tourism in Korea. J. Travel Res. 2018, 57, 1-17. [CrossRef]

41. Damala, A.; Hornecker, E.; van der Vaart, M.; van Dijk, D.; Ruthven, I. The Loupe: Tangible Augmented Reality for learning to look at ancient greek art. Mediterr. Archaeol. Archaeom. 2016, 16, $73-85$.

42. Deliyiannis, I.; Papaioannou, G. Augmented Reality for archaeological environments on mobile devices: A novel open framework. Mediterr. Archaeol. Archaeom. 2014, 14, 1-10.

43. Martínez-Graña, A.; González-Delgado, J.Á.; Ramos, C.; Gonzalo, J.C. Augmented Reality and Valorizing the Mesozoic Geological Heritage (Burgos, Spain). Sustainability 2018, 10, 4616.

44. Chen, W. Historical Oslo on a Handheld Device-A Mobile Augmented Reality Application. Procedia Comput. Sci. 2014, 35, 979-985. [CrossRef]

45. Cranmer, E.E.; tom Dieck, M.C.; Jung, T. How can Tourist Attractions Profit from Augmented Reality? In Augmented Reality and Virtual Reality: Empowering Human, Place and Business; Jung, T., tom Dieck, M.C., Eds.; Springer International Publishing: Manchester, UK, 2018; pp. 21-32.

46. Bekele, M.K.; Pierdicca, R.; Frontoni, E.; Malinverni, E.S.; Gain, J. A Survey of AugmentedVirtual, and Mixed Reality for Cultural Heritage. J. Comput. Cult. Herit. 2018, 11, 7:1-7:36. [CrossRef]

47. Kysela, J.; Štorková, P. Using Augmented Reality as a Medium for Teaching History and Tourism. Procedia-Soc. Behav. Sci. 2015, 174, 926-931. [CrossRef]

48. Boboc, R.G.; Girbacia, F.; Duguleana, M.; Tavčar, A. A handheld Augmented Reality to revive a demolished Reformed Church from Brasov. In Proceedings of the VRIC 2017-19th ACM Virtual Reality International Conference, Laval, France, 22-24 March 2017; ACM: New York, NY, USA, 2017. Available online: https:/ / dl.acm.org/citation.cfm?id=3110311 (accessed on 15 October 2018).

49. Tan, K.L.; Lim, C.K. Digital heritage gamification: An augmented-virtual walkthrough to learn and explore historical places. In Proceedings of the 2nd International Conference on Applied Science and Technology 2017 (ICAST'17), Langkawi, Kedah, Malaysia, 3-5 April 2017. Available online: https:/ / aip.scitation.org/ doi/pdf/10.1063/1.5005472?class=pdf (accessed on 16 October 2018).

50. Roussou, M. Virtual Heritage: From the Research Lab to the Broad Public. In Proceedings of the VAST 2000 Euroconference, Arezzo, Italy, 24-25 November 2000; Oxford, A., Ed.; Archaeopress: Oxford, UK, 2000; pp. 93-100.

51. ICH. Available online: https://ich.unesco.org/en/what-is-intangible-heritage-00003 (accessed on 5 December 2017). 
52. Hincapie, M.; Diaz, C.; Zapata, M.; Mesias, C. Methodological Framework for the Design and Development of Applications for Reactivation of Cultural Heritage: Case Study Cisneros Marketplace at Medellin, Colombia. J. Comput. Cult. Herit 2016, 9, 1-24. [CrossRef]

53. Gao, Y.; Wu, X.; Zhang, Y.; Shen, Y.; Yang, X. The value evaluation system and applications of digital cultural resources. In Proceedings of the 6th International Conference on Information Management, Innovation Management and Industrial Engineering, Xi'an, China, 23-24 November 2013. Available online: https:/ / download.atlantis-press.com/article/20591.pdf (accessed on 18 September 2018).

54. Santos, M.E.C.; Taketomi, T.; Sandor, C.; Polvi, J.; Yamamoto, G.; Kato, H. A usability scale for handheld augmented reality. In Proceedings of the 20th ACM Symposium on Virtual Reality Software and Technology, Edinburgh, Scotland, 11-13 November 2014; ACM: New York, NY, USA, 2017; pp. 167-176.

55. Ko, S.M.; Chang, W.S.; Ji, Y.G. Usability Principles for Augmented Reality Applications in a Smartphone Environment. Int. J. Hum. Comput. Interact. 2013, 29, 501-515. [CrossRef]

56. Yáñez Gómez, R.; Cascado Caballero, D.; Sevillano, J.-L. Heuristic Evaluation on Mobile Interfaces: A New Checklist. Sci. World J. 2014, 19, 434326.

57. Tsai, T.-H.; Chang, H.-T.; Yu, M.-C.; Chen, H.-T.; Kuo, C.-Y.; Wu, W.-H. Design of a Mobile Augmented Reality Application: An Example of Demonstrated Usability. In Universal Access in Human-Computer Interaction. Interaction Techniques and Environments: 10th International Conference, Toronto, ON, Canada, 17-22 July, 2016; Springer International Publishing: Basel, Switzerland, 2017.

58. Schaeffer, S.E. Usability Evaluation for Augmented Reality. Department of Computer Science, University of Helsinki, 2014. Available online: https://core.ac.uk/download/pdf/33725105.pdf (accessed on 20 February 2019).

59. Santos, M.E.C.; Polvi, J.; Taketomi, T.; Yamamoto, G.; Sandor, C.; Kato, H. Toward Standard Usability Questionnaires for Handheld Augmented Reality. Ieee Comput. Graph. Appl. 2015, 35, 66-75. [CrossRef] [PubMed]

60. Han, D.-I.; Jung, T. Identifying Tourist Requirements for Mobile AR Tourism Applications in Urban Heritage Tourism. In Augmented Reality and Virtual Reality: Empowering Human, Place and Business; Jung, T., tom Dieck, M.C., Eds.; Springer International Publishing: Manchester, UK, 2018; pp. 3-20.

61. Javornik, A. Directions for Studying User Experience with Augmented Reality in Public. In Augmented Reality and Virtual Reality: Empowering Human, Place and Business; Jung, T., tom Dieck, M.C., Eds.; Springer International Publishing: Manchester, UK, 2018; pp. 199-210.

62. Střelák, D.; Škola, F.; Liarokapis, F. Examining User Experiences in a Mobile Augmented Reality Tourist Guide. In Proceedings of the 9th ACM International Conference on Pervasive Technologies Related to Assistive Environments, Corfu Island, Greece, 29 June-1 July 2016; pp. 1-8. Available online: https:/ / www. fi.muni.cz/ \{\}liarokap/publications/PETRA2016.pdf (accessed on 29 September 2018).

63. Rese, A.; Baier, D.; Geyer-Schulz, A.; Schreiber, S. How augmented reality apps are accepted by consumers: A comparative analysis using scales and opinions. Technol. Forecast. Soc. Chang. 2017, 124, 306-319. [CrossRef]

64. Georgiou, Y.; Kyza, E.A. The development and validation of the ARI questionnaire: An instrument for measuring immersion in location-based augmented reality settings. Int. J. Hum. Comput. Stud. 2017, 98, 24-37. [CrossRef]

65. Haugstvedt, A.C.; Krogstie, J. Mobile augmented reality for cultural heritage: A technology acceptance study. In 2012 IEEE International Symposium on Mixed and Augmented Reality (ISMAR), Georgia Tech, Atlanta, USA, 5-8 November 2012; IEEE Computer Society: Washington, DC, USA, 2017.

66. Tango. Available online: https:// developers.google.com/tango/ (accessed on 27 December 2017).

67. 3DS MAX. Available online: https://www.autodesk.com/products/3ds-max/overview\# (accessed on 4 January 2018).

68. Makehuman. Available online: http:/ / www.makehumancommunity.org/ (accessed on 2 January 2018).

69. Blender. Available online: https://www.blender.org/ (accessed on 2 January 2018).

70. Mixamo. Available online: https://www.mixamo.com/\#/ (accessed on 2 January 2018).

71. Unity. Available online: https:// unity3d.com/ (accessed on 3 January 2018).

(C) 2019 by the authors. Licensee MDPI, Basel, Switzerland. This article is an open access article distributed under the terms and conditions of the Creative Commons Attribution (CC BY) license (http:/ / creativecommons.org/licenses/by/4.0/). 